\title{
FORPIBID-RP E A POLITIZAÇÃO COMO ENFRENTAMENTO AO ENSINO REMOTO
}

Forpibid-rp and politicization as a means of confronting remote education

Forpibid-rp y politización como medio de afrontar la educación a distancia

Nilson de Souza Cardoso* Sueli Guadelupe de Lima Mendonça**

https://doi.org/10.38117/2675-181X.formov2020.v2i2n4.647-654

\section{RESUMO}

Vivemos um cenário de transformação intensa em decorrência dos efeitos da pandemia causada pela Covid-19, impactando direta e frontalmente a educação. A docência e o cotidiano escolar foram modificados para novos contextos em ambientes virtuais, marcados por precariedades e exclusões. É nesse processo ascende um novo modo de ensinar e de aprender, o remoto. A reflexão relaciona o recomeço dos programas Residência Pedagógica e Pibid, resgatando trajetórias de luta, conquistas e o contexto que requer articulação política na formação e na atuação docente.

PALAVRAS-CHAVE: Pibid, Residência Pedagógica, Atividade Remota.

\section{RESUMEN}

Estamos viviendo un escenario de intensa transformación por los efectos de la pandemia provocada por el Covid-19, que impacta directa y directamente en la educación. La vida docente y escolar se trasladó a nuevos contextos en entornos virtuales, marcados por la precariedad y las exclusiones. Es en este proceso que asciende una nueva forma de enseñar y aprender, la remota. La reflexión se relaciona con la reanudación de los programas Residencia Pedagógica y Pibid, rescatando trayectorias de lucha, logros y este escenario que requiere articulación política en la formación y desempeño docente.

PALABRAS CLAVE: Pibid, Residencia Pedagógica; Actividad Remota. 


\begin{abstract}
We are experiencing a scenario of intense transformation due to the effects of the pandemic caused by Covid-19, directly and directly impacting education. Teaching and school life were changed to new contexts in virtual environments, marked by precariousness and exclusions. It is in this process that a new way of teaching and learning ascends, the remote. The reflection relates to the resumption of the Pedagogical Residency and Pibid programs, recovering trajectories of struggle, achievements and this scenario that requires political articulation in teacher training and performance.
\end{abstract}

KEYWORDS: Pibid, Residência Pedagógica, Remote Activity.

\title{
A pandemia e o ensino remoto
}

Ainda não se consegue mensurar o impacto da Pandemia causada pela Covid-19 e pelas medidas de isolamento social, levará tempo para que se possa compreender e dimensionar as mudanças dele decorrentes nas diversas esferas da vida social. A precariedade dos serviços públicos, acentuada com a Emenda Constitucional no 95/2016, aprovada no Governo Temer, deixa ainda mais evidente a necessidade de investimentos públicos nas áreas sociais. Nunca o país precisou tanto de ciência, tecnologias e políticas públicas e, infelizmente, tem tão pouco a oferecer para o enfrentamento dessa crise, que depende do Sistema Único de Saúde e de seus servidores, apesar de toda a precarização e desvalorização impostas por medidas governamentais.

Na educação, a perversidade dos efeitos da Covid-19 ampliou a pressão sobre a categoria docente, funcionários e estudantes, especialmente das escolas públicas da educação básica, que se encontram em situação de risco, não só com a vida, mas também em seu direito à educação e às condições dignas de trabalho. O Estado brasileiro tem se mostrado incapaz de propor medidas consistentes para solucionar os problemas atuais. Arremedos e improvisos, a adoção de pacotes educacionais e plataformas de aprendizagens surgem como solução para os problemas emergentes, na verdade, trazem com o ensino remoto uma versão precarizada e limitada da modalidade de Educação a Distância (EaD), dispensando seus elementos essenciais, em especial, a formação e as garantias de acesso e condições de trabalho. A pauperização das reflexões sobre as necessidades e possibilidades da Escola e de seus profissionais, tem, neste momento, servido apenas para transpor e agravar todas as desigualdades que já marcam a educação pública com ampliação para a maior parte da população. 
FORPIBID-RP e a politização como enfrentamento ao ensino remoto

Há muito percebe-se a ausência de uma reflexão pela escola sobre a sociedade contemporânea, em especial sobre as mudanças advindas do avanço das tecnologias e seu impacto na vida social e institucional. Esse descompasso entre escola e tecnologias, entre outros fatores, vem dificultando transformações no processo pedagógico, que, por um lado, expressam a falta de compromisso do governo com esta questão e, por outro, evidencia o sucateamento da infraestrutura da escola e precarização da formação e condições de trabalho docente. O hiato provocado pela pandemia no cotidiano escolar poderia ser ocupado por essa reflexão de fundo, contextualizada nos questionamentos permanentes do trabalho pedagógico: por quê, para que, para quem, como, quando, onde e os meios para ensinar. Ir além da retórica saída no uso de Tecnologias Digitais da Informação e Comunicação (TDIC), exclusivamente, pois há, ainda, realidades "analógicas", desiguais social e economicamente, que o acesso à educação, por meios digitais, só agravará as distâncias para as os contextos "virtuais".

Nesse caminho, a "virtualização da educação", o ensino remoto, parece ser a tentativa de colocar a vida numa normalidade que já não existia e tão pouco voltará ao que vivíamos. Fazer a transposição de algo planejado para a ação pedagógica presencial para o modo online é mais um passo da improvisação que tanto se recrimina na educação. Num passe de um clique tudo foi possível ser ajustado aos meios digitais, sem planejamento adequado, de modo açodado para dar conta de conteúdos curriculares, ou seja, as disciplinas. As aulas por conferências online ou gravadas em vídeo, até pela sua limitação, centram foco apenas nos conteúdos e na disciplina como se só estes fossem o objeto da educação, do ensino e da aprendizagem (SARAIVA; TRAVERSINI; LOCKMANN, 2020). Docentes fazem suas transmissões e sobrecarregam os aprendizes do outro lado da tela com uma infinidade de leituras, atividades e comentários ou reflexões, como se não houvesse amanhã.

As novas características das relações sociais advindas da pandemia também impactaram a EaD, que de modalidade de ensino passou a ser vista como a única solução possível frente ao isolamento, via atividades remotas, que atingiu não só a educação, mas o trabalho de modo geral, com a instituição do teletrabalho, trabalho remoto, home office. $\mathrm{O}$ ressignificado social da $\mathrm{EaD}$ foi se moldando, determinado pelas condições objetivas da sociedade e sistemas de ensino e desafiando a limitação teórica e prática daqueles que deveriam promover formação qualificada dos profissionais da educação para o chamado ensino remoto.

O fato das atividades remotas se tornarem a panaceia dos problemas derivados do isolamento social expressa uma concepção imediatista do problema e se alinha à fetichização em torno do uso das TIDC. É de fato encantador utilizar uma ferramenta que agrega pessoas em espaços distintos em um mesmo momento, é mágico utilizar recursos que promovam outras formas conduzir os processos pedagógicos, como aqueles presentes em plataformas virtuais de aprendizagem. Dinamizar conceitos, formas e imagens, por 
vezes não traduzíveis por linhas escritas ou desenhos bidimensionais e estáticos. Envolver e integrar as multimídias (imagem, som, texto) ao passe de cliques é algo impensado num passado recente e um reclamo da atualidade. Porém o clique mágico também desnudou o fosso das desigualdades sociais, onde as restrições econômicas ao grupo mais pobre da sociedade brasileira, presente na base social da escola pública, se materializam objetivamente, já que este não tem equipamentos, espaço adequado e acesso à internet. Não é possível continuar a desconsiderar esse dado no que se refere o acesso às atividades remotas dos estudantes pobres de todos os níveis de ensino, pois estamos bem próximos do aprofundamento de um problema estrutural da educação brasileira: a evasão em decorrência do expoente da exclusão digital.

Um outro aspecto importante a ser discutido é a mercantilização da educação como meio da expansão do capital (ANTUNES, 2020) diretamente ligado às empresas internacionais como Google (Alphabet), Microsoft e Zoom, que rapidamente se colocaram como provedores, quase exclusivos, no atendimento às atividades remotas em diferentes dimensões (softwares, plataformas, equipamentos, assessorias, etc.). A entrada dessas empresas, principalmente no setor público, tem significado abrir mão de pesquisas em tecnologias livres, já desenvolvidas por universidades públicas, porém enfraquecidas pela conjuntura atual e opção política de governo e instituições. Outro elemento preocupante é a exposição de direitos de uso de imagem e de autoria de docentes e estudantes, decorrentes dessa adesão apressada, envolvendo um valioso banco de dados, com imagens e de informações, fruto de reflexões desprotegidas.

Tais mudanças inseridas no processo de precarização do trabalho, em que docentes não têm vínculos com escolas e universidades, fenômeno chamado de "uberização" (SILVA, 2019; ANTUNES, 2020), avançam para novas características, a qual denominado como a "youtuberização" da educação, cuja invisibilidade sobre roteirizar, produzir e dirigir vídeos, cuidando da luz, do cenário, do som e da edição, dos atendimentos de chats e mensagens que chegam com comentários e dúvidas, obriga professoras(es) a cumprir múltiplos papéis, imbricando trabalho e vida pessoal, sem contar com apoio das instituições de ensino, liberando ainda mais o Estado no provimento da educação. Por outro lado, na fetichização do uso das TDIC e das redes sociais, pode levar docentes a fazer um post, esperar pelos likes, marcar uma live e comemorar os muitos views... - quem tiver mais seguidores, vai virar trending teachers.

\section{E o que fazer?}

É nesse contexto maior, que os programas da Capes Residência Pedagógica (RP) e Programa Institucional de Iniciação à Docência (Pibid) deverão iniciar suas atividades em 2020, num cenário de isolamento social. Recomeço desses Programas chega com alguns avanços frente ao edital de 2018, como: a garantia de retorno de coordenadoras, 
FORPIBID-RP e a politização como enfrentamento ao ensino remoto

preceptoras, supervisoras e orientadoras, após período do exercício pleno da maternidade; fim da exigência de equivalência da participação de residentes como estágio curricular obrigatório, resguardando a tão atacada autonomia universitária; o fim de descontinuidade institucionalizada no RP, com uma imposição de "quarentena" de 12 meses para coordenadoras(as) do RP e, ainda hoje contraditória devolução de bolsas por residentes, que não integralizarem os módulos previstos, com regras menos draconianas que do edital.

Os novos editais trazem grave retrocesso: a introdução de áreas prioritárias, destinando 60\% das bolsas para os núcleos envolvendo Matemática, Física, Química, Biologia, Ciências e Alfabetização, sendo essas eleitas como áreas privilegiadas. Em complemento, no caso da alfabetização, há a exigência do projeto ser alinhado à atual política nacional de alfabetização, pautada no método fônico e em evidências, já contraposto por outras pesquisas e análises (MORTATTI, 2019). A ideia de áreas prioritárias implica em áreas não prioritárias, nos editais Capes definidas como áreas gerais, claramente indicadas: Arte, Educação Física, Filosofia, Geografia, História, Informática, Língua Inglesa, Língua Espanhola, Sociologia, Intercultural Indígena, Educação do Campo e Pedagogia.

O fato inquestionável é a ruptura da concepção de educação básica em que todas as áreas de conhecimento são constitutivas dessa fase da escolarização, não podendo ser restrita a esta ou aquela área do conhecimento. Ao focar nas áreas prioritárias, constatouse o menor espaço para áreas das ciências humanas, arte e educação física, relegando-as a um lugar subalternizado (SIMÕES, 2017). A destinação dos outros $40 \%$ de bolsas para a áreas gerais, consideradas como não prioritárias, implicou duplo corte para os cursos das licenciaturas dessas áreas, reforçando, por um lado, prejuízos à educação como processo formativo estruturado por todos os seus componentes curriculares $\mathrm{e}_{2}$ por outro, favorecendo o projeto baseado numa lógica empresarial e liberal.

Ainda no rol das medidas impositivas e vinculadas ao reformismo educacional, tal como acontece em outros elementos das políticas educacionais, os editais do RP e PIBID privilegiaram iniciativas institucionais que aderissem à Base Nacional Comum Curricular e a lógica de habilidades e competências. Essas, por sua vez, circunscritas a um pragmatismo aplicacionista de "objetos de conhecimento", expressando projeto de esvaziamento curricular, sejam de conteúdos ou das autonomias escolares e docentes.

E o que fazer? A diretoria do Forpibid-rp avalia que o momento atual é para acumular forças em nossas bases, fortalecendo o diálogo e a reflexão. Nesse momento de incertezas, a implementação dos Projetos Institucionais do Pibid e RP nas IES e nas Escolas parceiras, deverá estabelecer diálogos sobre as medidas assumidas e seu amadurecimento, já que as soluções não estão postas e isso demandará profunda 
avaliação, organizada de forma conjunta entre as instituições parceiras, sobre os trabalhos a serem desenvolvidos por todas e todos nas escolas.

\section{Qual escola queremos?}

Em síntese, o impacto das atividades remotas na educação atinge diretamente a docência - com implicações imediatas e consequências profundas - na formação, na atuação, na saúde do(a) trabalhador(a) e condições de trabalho. O estresse da(o) docente frente a exigência de adaptação aos novos/diferentes modos de execução de seu trabalho aprofunda um desgaste já existente no trabalho presencial, o aumento contínuo de carga horária, acrescido de muitas horas defronte ao computador; comunicação virtual com alunos; aulas síncronas e assíncronas. A nova forma de "aula" - chats, e-mail e Whatsapp - cria um novo tipo de isolamento, aquele que dificulta a interação com os alunos e compromete o processo pedagógico.

A virtualização dos processos educacionais alimenta um setor do capital que intensifica a exploração das(os) trabalhadoras(es) da educação e demanda nossa resistência, que começa na denúncia dessas falsas soluções, ausências da participação de docentes, estudantes e familiares, cuja exclusão digital deixará milhares de jovens sem acesso a um direito basilar, a educação. O agora é, mais do que nunca, tempo para perguntar: qual escola queremos? As incertezas ainda são enormes, mas temos convicção de que a adoção de medidas aligeiradas implicará em baixa qualidade na educação, acentuará as desigualdades sociais e servirá para fragilizar o papel primordial da docência na Educação Básica e Superior no país.

Esse preocupante cenário revela a importância da escola pública e do ensino presencial, pois, por um lado, é esta combinação que tem garantido o acesso das camadas mais pobres à educação. Por outro, revela que uma mudança drástica na modalidade de ensino requer, mais do que nunca, planejamento, infraestrutura, formação e suporte adequados para os sujeitos envolvidos para que haja o ato pedagógico em sua concretude: ensinar e aprender. A EaD e sua versão pragmática de atividades remotas, presentes no ensino presencial, não têm se mostrado o melhor caminho para a educação, pois não servem a todos e nem a todas formas de educar. E tão pouco podem substituir a escola e a universidade, nem tornar o(a) professor(a) um(a) operador(a) de app.

Toda essa trajetória de enfrentamentos e resistências têm proporcionando a professoras(es) e licenciandas(os) uma formação política, tão necessária ao exercício profissional da docência. Nesse processo, a análise da conjuntura e compreensão da correlação de forças nos revelam cenários, possibilidades de atuação e contradições a serem enfrentadas. 
FORPIBID-RP e a politização como enfrentamento ao ensino remoto

Os desafios, como vêm se inserindo ao longo da história brasileira, continuam sendo muitos e complexos, potencializados pela crise da pandemia, o que exigirá de todas(os) o compromisso com a educação pública, laica, democrática, socialmente referenciada para todos e que esta consiga superar a resistência e de fato ser a educação praticada. É momento de refazer e fortalecer relações e compreender que a formação e atuação docente envolvem, como em nenhum outro tempo, articulação política.

\section{Referências}

ANTUNES, R. Coronavírus: o trabalho sob fogo cruzado. 1 ed. São Paulo: Boitempo, 2020.

MORTATTI, M. R. L. Brasil, 2091. Olhares: Revista do Departamento de Educação da Unifesp, vol. 7, n.3, p. p. 17-51, 2019.

SARAIVA, K.; TRAVERSINI, C.; LOCKMANN, K. A educação em tempos de COVID19: ensino remoto e exaustão docente. Práxis Educativa, Ponta Grossa, v. 15, e2016289, p. 1-24, 2020. Disponível em: https://www.revistas2.uepg.br/index.php/praxiseducativa. Acesso em 21 de agosto de 2020.

SILVA, A. M. A uberização do trabalho docente no Brasil: uma tendência de precarização no século XX. Revista Trabalho Necessário, Niterói, v.17, no 34, set-dez, 2019. Disponível em: https://periodicos.uff.br/trabalhonecessario/article/view/38053/ 21780. Acesso em 21 de agosto de 2020.

SIMÕES, W. O lugar das Ciências Humanas na "reforma" do ensino médio. Revista Retratos da Escola, Brasília, v. 11, n. 20, p. 45-59, jan./jun, 2017. Disponível em: http//www.esforce.org.br. Acesso em 21 de agosto de 2020.

Recebido em: 10 ago. 2020.

Aprovado em: 11 ago. 2020.

* Nilson de Souza Cardoso é professor da Universidade Estadual do Ceará (Uece) no curso de Licenciatura em Ciências Biológicas (Campus Crateús) e no Mestrado Profissional em Ensino de Biologia em Rede Nacional (Profbio). Membro do grupo de pesquisa Educação, Cultura Escolar e Sociedade (EDUCAS) e doutorando no PPGE/Uece. Presidente do Fórum de Coordenadores Institucionais do Pibid e Residência Pedagógica (FORPIBID-RP).

E-mail: nilson.cardoso@uece.br

https://orcid.org/0000-0003-3214-8942 
** Sueli Guadelupe de Lima Mendonça é professora do Departamento de Didática e docente do Programa de Pós-Graduação em Ciências Sociais da Unesp/Marília. É coordenadora do ProfSocio/Unesp e Líder do Grupo de Pesquisa "Implicações pedagógicas da teoria Histórico-Cultural". É Coordenadora Institucional do RP/UNESP e Vice-presidente do Fórum de Coordenadores Institucionais do Pibid e Residência Pedagógica (FORPIBID-RP).

E-mail: sueli_guadelupe@uol.com

https://orcid.org/0000-0003-4585-4088 